\title{
Interweaving Conceptual and Substantial Problems of Writing Instruction: Socio Reflective on Exploring Hortatory and Analytical Exposition
}

\author{
${ }^{1}$ Wiwiek Afifah, ${ }^{2}$ Anida Sarudin \\ ${ }^{1}$ Graduate School of Yogyakarta State University, Indonesia \\ ${ }^{2}$ Universiti Pendidikan Sultan Idris, Malaysia \\ wiwiekafifah.2018@student.uny.ac.id
}

\begin{abstract}
This paper explores interweaving conceptual and substantial problems of teaching writing skills for analytical and hortatory exposition texts. Under the narrative inquiry, five English teachers' personal life experiences were analyzed. Having been analyzed, the findings reveal: (1) students were still weak in understanding the concept of the two texts (social function, generic structure, and lexicogrammatical features of the text). (2) Students' confusion to distinguish the two genres is supported by the condition that they do not learn the genres in their primary language. (3) The students are not accustomed to expressing their arguments whereas in analytical and hortatory texts the main points are presenting sequences of arguments in the body of the text. (4) Students have low motivation to read therefore it is hard for them to propose the suggestion and make reiteration in the end of hortatory and analytical exposition texts, and (5) lexicogrammatical features or the grammar that are commonly used in those texts are complex for the students in that level.
\end{abstract}

Keywords: analytical, hortatory exposition, writing, instruction

How to Cite: Afifah, W., \& Sarudin, A. (2020). Interweaving conceptual and substantial problems of writing instruction: Socio reflective on exploring hortatory and analytical exposition. English Language Teaching Educational Journal, 3(1), 26-40.

\section{INTRODUCTION}

The The issues of writing instruction reported by two international giant companies: Taylor and Francis online and SAGE journal reach more than 530.796 articles. These obvious facts show that writing has attracted many researchers to investigate. It is then assumed that writing provides not only problems but also interesting challenges. However, in a local context such as in Indonesia, the issue of writing mainly for English as a foreign language exposes not only conceptual but also substantial problems. This skill is offering a total confusion that automatically attracts a number of scholars to endeavor and cleave the hindrances.

The uncovering problems faced by teachers are assumed to be the primary factors supporting the failure of writing instruction. Additionally, those facts become worse when the mindset that writing is difficult when compared with another. Relating to that case, Richards \& Renandya (2003) state that writing covers a highly complex skill. Furthermore, they express that target language authors have to pay attention to higher level skills encompassing planning and organizing as well as the level of skills for spelling, punctuation, word choice, and so forth. Furthermore, Rahmatunisa (2015) found that there are some points supporting the problems in teaching and learning of English writing as a foreign language in Indonesia: linguistics, cognitive, and psychological problems. A piece of information has also been found by the researchers during the observation in March 2018. Through participatory observation in the preliminary research, three problems were found: (1) principal learning experience, (2) instructional materials, and (3) students' self- 
concept in writing. The principal learning experience mostly applied in the classroom did not match to the learners' today condition. In addition, the analytical and hortatory exposition texts also created problems.

As a matter of fact, it is true that learning writing is not always easy although students have learnt English for many years on their previous level. Adding to the argument, Kroll (1990) states that teaching EFL is complex and needs an ongoing process to become a good author. Writing a text in target language needs appropriate strategy. Teachers are not only conceptually ready with the writing but also be able to encounter all the practical problems faced by the learners. Relating to analytical and hortatory exposition, those genres are recommended to learn by the students in Senior High School. However, they still find it difficult to master. Teaching and learning how to write those genres are not trivial. Analytical exposition texts are characterized by thesis, arguments, and reiteration while hortatory exposition texts are started by thesis, arguments, and closed by recommendation. Since their differences are not obvious, many students complain of their confusion when learning them. Dealing with the problems, the researchers observed that students were still weak in comprehending those texts' concepts. They got trouble distinguishing their differences such as their social functions, the generic structures, and the language features which are commonly used in these texts. Therefore, the interweaving between the concept of hortatory and analytical text make the learners feel confused.

Realizing that phenomenon, this study aims to systematically explore the problems of teaching hortatory and analytical exposition texts based on a socio-reflective. The socioreflective refers to the belief that the process of learning construction is built by a social process (Yancey, 2015). In this study, reflective refers to the thinking process based on the student's account, perception, inquiry and also judgment through the sequences of interaction (between teachers and students) to support the process of making meaning through writing activities. Under the narrative inquiry, the stories of five teachers (teaching in public and private of senior high schools) are used as the primary information.

\section{General concept of writing}

Writing can be understood as the attempt to communicate, plan, think, imagine, remember, collect and access information, or store ideas in memory (Moore-Hart, 2010). By doing writing, an author will represent and reclaim their experiences through their writing for the readers. The writing activity will be easier and naturally when students start to write by drawing and writing. Even, writing will emerge more easily when the students will write their experiences. Additionally, students will become more interested in the writing when they are facilitated to write centered around themselves. Here is the visualization of the circle of ideas in writing activities.

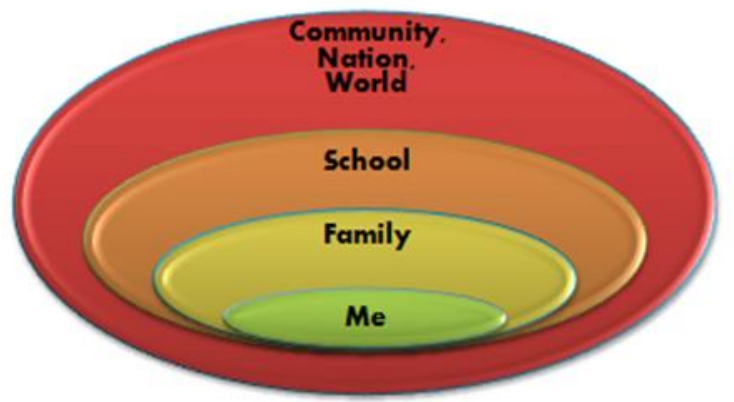

Figure 1. The Circle of Ideas 
Richards \& Renandya (2003) highlight that generating and organizing ideas refers to translating them into a readable text. Those are the most obvious factors supporting writing to become a difficult skill for target language learners. Moreover, the skills involved in writing is very complex. Regarding the complexity of writing skill, Harris (1969) reminds that at least there are five components in the writing process: 1) content: refers to the substance of the writing or it can be the idea expressed, 2) form: refers to the organization of the content, 3) grammar: roles as the guidance to control the development of grammar form and pattern. 4) Style: refers to the choice of the structure and lexical items to give a particular tone or flavor to the writing itself. 5) Mechanics: refers to the use of graphic conventions of the language. The five components proposed by Harris at least should be taken into account when writing. Then for teachers, they should take a role in translating the writing principles into practice. The practice to produce optimal learning benefits, they should constantly record, consider, and analyze what they have done in the classroom then use their reflective experiences as a basis for improving their instructional practice (Richards \& Renandya, 2003).

Based on the theories recommended by some scholars, it is obvious that in teaching writing, teachers should pay attention to those conceptual aspects. Dealing with the issue, Oshima and Hogue (1991) state that writing is a process. Raimes (2003) also explains that the process is proven by the effort and a commitment to think about writing content, fluency, personal voice, and revising. When referring to the view of process approach, that proposes and emphasizes on how a piece of writing is constructed. This notion refuses that it is not necessary to give a great attention only to the writing as a product. The principles of conceptual process approach always pay attention to the product but at an appropriate stage in the process.

Regarding writing activities, Raimes (2003) proposes some steps in planning the course: 1) ascertaining goals and institutional constraints, 2) deciding on theoretical principles, 3) planning content, 4) weighing the elements, 5) drawing up syllabus, 6) selecting materials, 7) preparing activities and roles, 8) choosing types and methods feedback, 9) evaluating the course, and 10) reflecting the teacher's experiences. Those ten steps should be pondered by teachers when they teach writing skills. Then when they are able to reflect these principles in their writing class, the concept of writing as a product as well as a process will appear in balance.

Along with Raime's postulate, Oshima \& Hogue (1991) explain that writing is a process, not a product. It can be understood that writing as a composition is always possible to review and revise, then review again. Another postulate is proposed by Moore-Hart (2010) that writing involves thinking, feeling, and communicating as well as including prewriting, drafting, revision, and editing. Here are the sequence activities encompassed in those stages.

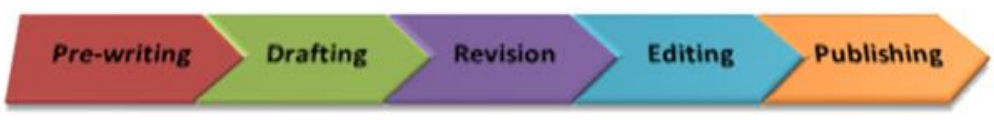

Figure 2. The Sequences of Writing Activities

In line with the notion that writing is a process, Seow (2003) explains that writing is broadly seen as comprising four main stages: planning, drafting, revising, and ending. The process of writing incorporates the four basic stages and the three other stages externally 
that are teachers, sharing, and evaluating as the post-writing. Meanwhile Brown (2007) convinces that the process relates to the activities such as association, storing a meaning and memorizing, transferring, generalization, and interference. If the word process refers to those terms, as explained by Brown, so all human life when involving language learning will have experienced the process stage. Process is human's characteristic.

\section{Genre-based approach}

Analytical and hortatory texts are part of genre-based (Wang, 2009). Learning and understanding those kinds of texts, students should understand the text characteristics such as its social function, generic structure, and its linguistics feature (Hyland, 2004). Additionally, teachers should help learners in building the knowledge thus they can understand the concept of the text (Alyousef, 2006).

One of the principles to master these texts is the ability to choose the issue. Thus, the learners will be able to arrange their argument in a good order (Ali, 2016). In addition, they should have the ability to think critically and to propose the best solution for the issue taken by them (Stapleton, 2001). Organizing their thoughts and ideas as the generic structure of the text as well arrange them in a logical sense then followed by evaluating the writing product is an important step to consider in writing activities.

Before teaching how to write an analytical and hortatory exposition, students should be taught the concept of those texts (Alfatia and Al-Hafizh, 2013) because their social functions are slightly different. When teaching these texts, teachers should explain their differences and give some examples related to the texts. Furthermore, the generic structure of the text for analytical encompasses: thesis, arguments, reiteration/summing up, then for hortatory $\mathrm{n}$ encompasses: thesis, arguments and recommendation. Their differences are small (Indrowaty et al., 2018). The linguistics features used in those texts focus on generic human and non-human participants, use of modality and modulation, few temporal conjunctive relations, reasoning expressed as verbs and nouns, use of material, relation and mental process, and the use of simple present tense (Henry and Roseberry 1996).

\section{Relevant of previous research}

In fact, the problems of teaching writing skills for analytical and hortatory exposition do not only happen in Indonesia. It is not merely for Indonesian students who face this problem but some overseas students also get the same difficulties. As Bilal et al. (2013) reported in their research that the problems of writing skill in Sargodha students commonly cover the influence of L1 on L2 Learning, effects of multicultural, multilingual and psychological factors, and effects of grammar teaching on English writing skills. Since a different language gives a different language concept, teaching of English writing as a foreign language is also influenced by those factors. Then multicultural and multilingual background also give great effects toward the learning process. Consequently, the raised problems transpire in writing processes need serious attention. Dealing with this issue, Hyland (2004) states that the entire teaching process must be compatible with social set up and cultural background, which they termed as 'situated cognition. In addition, Al.gomoul (2011) also stated that there are two activities needed to be considered in teaching writing dealing with relating to the social aspect building the context to establish a balance of fluency and accuracy and integrating the knowledge of the language skills.

Having conceptually and practically exploring the issue of writing of analytical and hortatory exposition, the researchers present the frame of thought. It is aimed to give a visualization of the discussion. This framework is also expected to control the description of the notion of this study. 


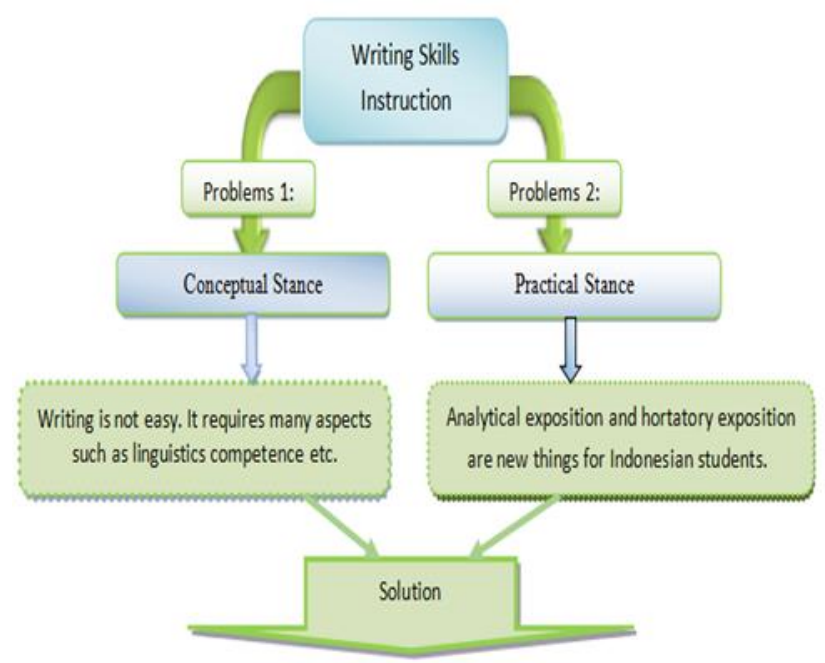

Figure 3. The Frame of Thought

\section{RESEARCH METHOD}

Narrative inquiry has been implemented in this study to explore these identified problems. With the enquiry model of narrative, it has been embraced to understand the participants' experiences in facing the problem of teaching hortatory and analytical exposition. As the study investigated the teachers in making interaction and relationships with their students, narrative inquiry was assumed to be the appropriate use as a research method to apply. It is because with narrative inquiry, the researcher will explore and expose how teachers handle the entire problems in their writing classroom (Clandinin and Connelly, 1995, 2000). With narrative inquiry, teachers can make a reflection of the complexity of life and experience through interaction from their personal and social situation, as well as persist their past, present and future condition they have experienced. With the meaning of conscious reflection, then teachers can improve their practical knowledge. Additionally, narrative inquiry can help teachers not only explore the meaning of all of them but also structuring the power in their teaching experiences (Bruner, 2000).

Since this research is positioned within a narrative understanding, thus participants involved in this research were teachers having experiences in teaching exposition and hortatory exposition writing. In addition, those who were willing to share their experiences in handling the problems. As it is assumed that different teachers have different stories to tell, therefore, this research only focused on how they traced the problems in teaching writing and how proposed the recommendation in their teaching practices. Data collection needed in this study were interviews, observations and gathering the students' writing.

Having collected the data needed, then the researcher compared patterns/themes of the problems during teaching analytical exposition and hortatory writing. The next step then interpreting them to make meaning from the pattern/themes based on the socio reflective approach. The data analysis is not a step by step procedure, but it was a simultaneous activity done during the initial analysis begun during the first interview or observation. 


\section{FINDINGS}

Having read the stories from the participants; the findings are presented in the following parts. They are divided into two groups: conceptual and practical problems. The former deals with problems related to the text such as its social function, its generic structure, its linguistic features of the text, and the learning principles in teaching genrebased. The latter deals with substantial problems happening during the teaching process. Those findings are presented and completed by direct quotations.

\section{Conceptual problems in teaching hortatory and analytical exposition texts}

The fist finding is about the conceptual problem derived from the texts. The students still get confusion and difficulties in identifying the purpose of these two texts. Since the texts have different generic structures and linguistics features, students get difficulties to identify. This finding can be traced from the following teacher's story quotations.

"In teaching analytical exposition, I explained the text function because I know that this is the most important information that they must know. I also explained the grammar to my students for they must learn the language features such as focus on using human and non-human participants and the use of modality as well as modulation in hortatory text. But it is not easy. Although, they admitted understand the material, but when they practice writing, some problems still frequently appear. I admit that students get difficulties in understanding the text social function". Field note-01-Teacher's storyl.

"Temporal conjunctive relations, reasoning to express verbs and nouns, use of material, relation and mental process should be used in hortatory text. In addition, the use of mental processes, material processes, relational processes, and the use of simple present tense should be emphasized as well. But, to apply those grammatical features in the writing skill is difficult. My students still need an intense guidance. As a matter of fact, I have 35 students in this class. I cannot give an intensive guidance to them. I just explain it in front of the class ...". Field note-05-Teacher's story5.

"On the other hand, the time allocation for English in Senior High School is only 90 minutes a week. Sometimes, I cannot predict the students' capability in achieving the learning outcome. Some I give additional time after class to help them in understanding the text. I can't imagine how regret students not being able to master the text, but I am predicting that these two text are bit difficult for them. I can predict how far they will achieve their progress although I give them intense guidance for them. The result is still not satisfying". Field note-02-Teacher's story2.

"To tell the truth, sometimes, I also feel confuse how to explain these texts to my students. They always said that "it is difficult Miss to write the argument I don't have any idea about that, this is very hard Miss, I don't have anything to write ...". Field note-03-Teacher's story3.

"yes I know about genre-based teaching principles, starting from building knowledge of filed until independent construction of text .... however, it is not easy to implement. I cannot apply it well in my teaching practice for some reasons ..." Field note-04-Teacher's story4.

\section{Substantial problems in teaching hortatory and analytical exposition texts}

The second finding deals with vocabulary, grammar of the target language and expressing as well as ordering the argument. Not being accustomed in expressing their arguments, students got difficulties in arranging their argument in analytical and hortatory 
texts. Furthermore, since students have limited general knowledge, it makes hard to propose the suggestion and reiteration in the end of hortatory and analytical exposition texts. Since teaching and learning English have a close connection to the social context, then the students' perception about seeing the text also influences their success in mastering these texts.

Here is the empirical evidence gained from the teachers' narrative inquiry from Yogyakarta public and private Senior High Schools teaching in social classes. The teachers also admitted that most of the students spend only limited time in reading. Even, they recognized that even their students were poor in writing a paragraph. This can be traced from the following stories.

"... teaching English in social study program, eehmmm .... it is not easy but it is challenging, actually, hehehe ... most of my students are boys, so sorry ... not all of them have good motivation in learning English ... I spend a great of time in classroom management ..." Field note-01-Teacher's storyl.

"... teaching or learning principles that are theocratized in genre-based is not easy to be implemented. Although, I know that is a good theory to implement in the teaching practice, but in fact, in my classroom, it doesn't work ...". Field note-01-Teacher's storyl.

" in a break time, I always ask them to read but they ignored. Yet, they want me to explain and retell the information, they prefer listening to my explanation and my information ....". Field note- 01 Teacher's story2.

"most of my students lack in understanding the issue. When I gave them a notion, they took a long time to give responses. When I tried to ask them, they admitted that they nevpr heard the issue before. On the other hand, the issues are famous and have been published in some new papers. From the communication, I knew that my students had few time to read." Field note-03-Teacher's story3.

"Since the main point of teaching writing or the basic competence is helping students to express their idea in order to create a text, I must support them to write a text. Yet, it needs a longer time to write in the classroom, then students requested to finis writing the text at home. Most of them cannot write the text in the classroom. They wrote it at their home. One of the reasons is that explanation and hortatory are new text for them ..." Field note-04-Teacher's story4.

"... the writing does not happen when they do not have ideas. In analytical and hortatory exposition, the main focus is how the students arrange their argument in the text and how they can propose the suggestion to the readers. The most prominent point in writing these text types, the students must strive themselves to read as much as possible to build their understanding and enrich their knowledge....however, students seems don't have good habit in reading ..." Field note-03-Teacher's story3.

As students have a low level of reading habit, they find learning the two texts is difficult. As consequently, the expression of the ideas and arguments are also awkward. It is a fact that writing both for analytical and hortatory texts needs not only ideas but also students' knowledge. Without having a good habit of reading, it will be difficult to express their argument as these texts demand them to explore and compare their reasons. Another 
fact is the cultural gap between Bahasa Indonesia and English. It is strange for Indonesian students to learn hortatory and analytical exposition since they only learn exposition text in Bahasa Indonesia. This difference brings other problems for students to put their ideas into a good order. Moreover, before they are able to write both for analytical and hortatory exposition, they should master the concept of the text such as the purpose of the text, the generic structure, and the grammar that must be used when writing the text.

"Sometimes, I felt confused in explaining the text since students always ask to give the example in Bahasa Indonesia. Since they never learn hortatory and analytical exposition in their native language. This brings a difficulty". Field note-01-Teacher's story2.

"Teaching English in Senior High Schools demanded me to be creative. I personally think that writing is the hardest skill to learn by my students. Some problem is frequently appear such as students lack of vocabulary, the confusion of using verb in the form of past and present, and some technical problems ..." Field note-01-Teacher's story3.

Teaching hortatory and analytical exposition texts are complicated for Indonesian students. The students are still reluctant to convey their opinion. They are not sure of their own argument. The low level of confidence also supports the problem. It creates the process of practice analytical and hortatory become blocked. Since the main point of teaching writing is helping the students express their idea, thus when they do not have ideas, the writing will never happen. In analytical and hortatory exposition, the main focus is how the students arrange their argument in the text and how they can propose the suggestion to the readers. The most prominent point in writing these text types, the students must strive themselves to read as much as possible to build their understanding and enrich their knowledge.

The cultural factor also contributes to the difficulties of writing analytical and hortatory exposition. Since the students have known that there is no separation in exposition when they learn Bahasa Indonesia, they need a longer time to understand those texts. The students must build their adaptation in comprehending the two different texts and it is not a simple thing for them. Fortunately, based on the teacher's story, there are some critical students who are curious to know much about the differences between the concept of exposition in Bahasa Indonesia and English. In this context, the teacher must be able to explain the content of the materials based on the students' level of understanding.

"Social classes are dynamic. Although most of them admitted that learning English is hard and sometime made me feel lazy to join the class, yet there are some critical students who always explore new things in their life...they demanded me to make a comparison between analytical and hortatory with Indonesian text...". Field note-01-Teacher's story4.

It is strange for Indonesian students to learn hortatory and analytical exposition texts. It is due to the fact that students only learn exposition text in their primary language, Bahasa Indonesia. This difference brings other problems for students to put their ideas into a good order. Moreover, before they are able to write both for analytical and hortatory exposition, they must understand the purpose of the text, the generic structure, and the grammar that must be used when writing the text.

For Indonesian teachers, teaching hortatory and analytical exposition for writing skills is complicated. It is because the students are reluctant to convey their opinion. It seems that they are not sure of their own argument and feel that they do not have something to say about the issues provided by the teachers in the classroom. On the other hand, some 
teachers also recognized that the issues taken for the materials relate to the learners' life. Here is the quotation from the interview

\section{DISCUSSION}

\section{Adjusting conceptual problems based on the social context}

In general, base and the socio-perspective, the problems of learning and teaching hortatory and analytical text are caused by a content and a context of the culture. Socioperspective in this discussion refers to the belief that problems found through the teachers' inquiry are related to the social context. This idea is supported by Stern (1991) that essentially, the process of teaching language and society cannot be separated as language and society are closely linked. The emerging problems are also assumed to be influenced by the social factors such as the aspects of the teacher and students' social life background, the role of language in the society, and how students use the language in their life. In addition, content in the perspective of socio-perspective refers to the language or the text learnt by the students.

Hortatory and analytical texts are the product of genre pedagogies which represent their culture. According to genre-based approach, every text naturally encompasses its social function, generic structure, and lexico grammatical features. The assumption that writing will be more acceptable if students are aware of what the target culture's mean are acceptable according to the belief. However, unfortunately many teachers teach those texts without contextualizing them to the cultural context. In connection to the theoretical-based, the empirical findings having a connection and influence each other are also influenced by the context where teachers and students build the context. The process of learning writing for analytical and hortatory exposition seems complicated because of the following reasons. First, it is because the students are not accustomed to expressing their arguments. This reflects the students' habit and the context that has brought them. Second, since the students have a low motivation to read any books they will never have sufficient information to share in their writing. This reason belongs to the students' mindset that is also greatly influenced by the context where they live. This is obvious that teaching writing skill of analytical and hortatory exposition is difficult as the context where the teaching and learning happen does not support.

From the social perspective, teaching writing should be initiated by building a context. With this effort, the teachers will be naturally involved and easily give a model to the students. Being involved in the context, they can encourage the students to have a good constructive habit such as reading some information independently in order to feel curious to get new knowledge. The teachers must motivate the students to read then write what they have understood about the topic. Teachers can help the students to write both for analytical and hortatory exposition texts by doing that strategy. It means that teachers will not only help the students in developing their linguistic competence but also communicative competence. Add to this, teachers can motivate them to have writing habit, adopting positive values from culture provided by the text learned by them and finally to think critically. Since teaching writing is aimed to help the students to produce a good text so students must be supported to write again and again as well as reading as much as possible. In line with this argument, Bilal et al. (2013) also state that developing writing skills is a slow and gradual process with the way how they think.

Either conceptual or substantial problems which have emerged are caused by the cultural bias. The fact that most of students get a bit confused to distinguish the two genres 
is supported by the condition that they do not learn the genres in their native language. In addition, the students are not accustomed to express their arguments. In spite of the fact that in analytical and hortatory texts, the main points are presenting sequences of arguments in the body of the text. A complex cultural bias happens in this case as two different cultures collide. The culture represented by the text and the culture owed by the students. Dealing with this phenomenon, Moore (2003) called it as a culture-based difference. To sum up, the culture-based difference is the heart which creates that problem.

The fact that students have low motivation on reading and on the other hand, the texts are the representation of the higher level of cultural society having a higher literature with a critical thinking has brought another problem. Therefore, if the student finds it hard to propose the suggestion and make reiteration in the end of hortatory and analytical exposition texts, that is normal. It is due to the condition that students never have been trained in their real life with the context they find in the target texts. Therefore, in teaching these two texts, teachers should touch the cultural aspect from the students' sides. After this point can be handled then another problem such as lexicogrammatical features and vocabularies that are commonly used in those texts can be handled. The failures of teaching hortatory and analytical texts might happen, if the teachers do not touch the culture either derived from students or from the text. Teachers should bring the two cultures in teaching and learning processes as the culture itself is represented in the text. From the perspective, Stern (1991) as inspired by Malinowski, explained that in language learning, context should be contextualized in student's life where they lived. Theoretically speaking, when culture is inserted into the learning process, it will be related to how the students use the language in their life, how they use the language in the interaction with their environment, and how students build their existence to the society with the text they have learned.

Based on the field note of the teachers' story, writing hortatory and analytical exposition are regarded as the troublesome skill for some teachers and students. Some existing researches which attempt to reveal wide range strategies in overcoming their obstacles in teaching writing have shown that writing skill demands a high effort both from teachers and students when they will do writing. This fact is also supported by Williams, Stathis, and Gotsch's (2008) finding that people are programmed to talk before they learn to read and write, and this holds true in second language teaching. The case is also supported by the real condition in our daily life that people spend much more time interacting orally with language rather than using language in its written form. Brown (2004) also highlights that every aspect of everyday life for 'common' people was carried out orally.

Brown (2004) states that it is also fully understandable the difficulty of learning to write in any language, even in the native language. Thus for teachers teaching writing should help the student to write. Then when dealing with writing at least there are two things to be involved: linguistics aspects and communicative competence (Bilal, et. all, 2013) and considering the cultural aspects. Teaching of writing skill as a foreign language even bestows a great burden for the language learners. It is obvious that writing in the first language will be very different from the target language. It is in line with Silva's argument (1993) as cited by Bilal, et. all, (2013) that learning a second language is usually different from the first language strategically, rhetorically and linguistically. Add to this, she points out that a written assignment created by the second language learners was syntactically and semantically loose. Regarding the previous arguments, some researchers such as Hyland (2003), Anees \& Raaxia (2007) in Bilal, et. all, (2013) state that the differences between L1 and L2 also affect the learners' thinking ability supported by social and psychological factors. For social factors, it encompasses social status, family background whereas psychological factor covers motivational level and age. 


\section{Investigating the substantial problems from the socio-reflective}

Language is the essential factor in human to support their social life (Stern, 1991). When learning the text, the linguistic features are automatically included in that text. However, students still find some problems in using grammar in that target language. To respond this problem, teachers should adopt the sociolinguistics perspective and psycholinguistic as suggested by some scholars such as from Malinovsky and Schumann as cited by Stern (1991). By Applying that theories, at least teachers will be able to adjust the context from the two cultures, conceptualizing the learning materials and principle learning during the teaching process. Moreover, teachers will consider how the process of their students in acquiring and learning the new texts for them.

By considering the cultural differences, teachers can design the language learning based on the classroom condition including the cultural background of the students. Stern (1991) in this issue suggested to bring learning as a training rather than as a real communication or as an introduction of the real new foreign culture. In line to this, Clark (2003) in Bilal et al. (2013) who points out that learner must be taught a writing process can be adjusted as the process of building and forming and developing mental association with acquiring new culture through the existence of the text. From this point, it can be understood that in order to have and get new knowledge of the text and having a good writing ability including exploring and proposing the ideas as well as linguistic competences, students must invest a great time to learn and to immerse in the target culture without ignoring their culture. With this strategy, practicing the grammar and arranging their ideas in a good order can be easily done. Naturally, learners will be able to select the appropriate words then put them in their appropriate position in the sentence. It is because their metal has been set based on the target culture.

\section{Socio reflective in term of teachers' teaching strategies}

In teaching hortatory and analytical exposition, teachers should implement a genrebased approach: building knowledge of the field, modelling of text, joint construction of text, and independent construction of text. However, teacher can integrate and considering the two social aspects such as culture represented from the text and students' culture. Teachers can take some issues relate to the students and school environment. Additionally, in the first phase, teachers can stimulate some social aspects. For instance, like what Bowkett's (2009) suggestion, there are some activities that can support the habit of doing writing taken from some famous authors. Bringing some public figures from the two culture such as the figure of Ernest Hemingway-sharpened pencils to get him in the mood to write, Marcel Proust-kept ripe apples on his desk. Then the sweet smell of the apples triggered the creativity flow, Anchors can be kinesthetic, olfactory (linked to smell), visual, auditory-or a blended these. Those kinds of activities can be used by the teachers to motivate the students in order they will love learning to write. Then for further learning and teaching activities in the classroom context, teachers can start the activities by doing prewriting to elicit the students' idea in the phase of join construction of text. It is a must for teachers to build a friendly cultural atmosphere in the teaching process since writing activities deal with organizing ideas into readable text and a complex requirement of linguistic inputs. In addition, designing an interest based on the students' social context is also necessary to do. By doing so, the listed problems in English writing classrooms will be successfully handled.

It cannot be denied that teaching language means teaching how to shape the context of the lesson (Kramsch, 1993). A student as an individual will be directly involved in the 
context and take an active participation. During the teaching process, the goal of the learning will be a fetus which controls the norm of interaction, learning activities, modalities and learning contents used as the primary resources. Considering Kramsch's idea, dealing with the English writing skill, teachers will never be the single player roles and judge as well as the critical evaluator of the student's finished product. The students' work will never be returned to students with some mistakes indicated or corrected. The legendary red pen which has always been a tool of the teacher's trade as McDonough \& Shaw (2003) will never happen. Yet, writing will be the holistic teaching and learning process where teachers and students are learning together to adjust the target culture. The process of evaluating the students' works will become the long and dynamic process to know each student's level of achieving the learning targets.

The notion that writing will never happen when students have never been aware of the target culture and their own culture give strong impact in this teaching process. In order to help the learners to understand the culture and get ease to find the idea to develop, teachers can implement the principle of teaching offered by some approaches from the sociolinguistic perspective. Teachers can relate the issues based on the student's social background. In addition, teachers can pay attention to the class characteristics, the culture in the classroom. Teachers can stimulate students' ideas by relating the issues with the currents phenomena in their students' life. Hortatory and analytical exposition texts can be integrated by exploring the issues happening in the local context. However, it is not easy to find those texts used as modelling in the teaching process. In this case, teachers are required to create their own text to be used as the modelling text to their students.

Regarding the previous explanation, thus teaching hortatory and analytical exposition texts based on the genre-based is tricky. The students are trained to understand not only the typical text type and its characteristics but also the historical reason behind that fact. However, the texts are not easy to be found in their real life. On the other hand, students are demanded to understand and to do next level - joint construction of text and do the independent construction of the text.

Therefore, students need a longer time to know and to understand the text. In addition, when they have finished writing their texts, peer writing or collaborative writing should also be conducted because those activities will stimulate the students to learn more and work together. Furthermore, they can get a self-reflection. This idea is anchored to the fact that writing is a valuable skill, and by doing this, it will reinforce the other language skills. Even it can help students to think critically. In line to the idea, Hess (2001) explains that through writing, students will learn and improve other skills such as grammatical and vocabulary. Through writing, teachers can help learners to internalize the cultural values they have learned from the texts and stimulate the learners' way of thinking.

By integrating the socio perspective, teaching writing of hortatory and analytical texts can enlarge the writing target. In addition, this can support the shifting from the preceding fidgetiness such as Gilstrap (1991) who reported that more than $84 \%$ of the writing done in the secondary schools was extremely narrow. It is limited in audience to the audience, to the teacher as examiner, with the purpose to inform or report. In essence, most writing was for tests and reports or as transactional. He further explains that based on the research conducted, it is proven that in teaching writing, it is necessary for a teacher to make sure who the audiences of the writing are for.

Among the problems told by the teachers' stories, an assessment was not touched by them in their field notes. On the other hand, it brings a crucial role in supporting teaching writing. Theoretically speaking, the assessment should be taken into consideration. Gilstrap (1991) proposed some points to be involved in the writing assessment such as the final product orientation and emphasizing on what and who is writing for. In line to that 
postulate, actually writing assessment covers complex aspects such as things related to psycholinguistics, sociolinguistics, and pragmatics. Those factors must be taken into account for the assessment. Then to cover those things, in teaching hortatory and analytical exposition, teachers must support the awareness of doing writing activities, actively giving feedback, designing a meaningful writing assignment, building a student's social context, as well as providing input or ideas before students start writing.

\section{CONCLUSION}

Having systematically explored the problem of teaching hortatory and analytical exposition texts based on a socio-reflective, the problems are grouped into two. A problem that relates to the text and to the substantial aspect of teaching and learning. Having explored the finding based on the social phenomenon, content, and context cannot be discarded from the classroom environment. Context refers to the things outside the text and content refers to the things inside the text. From the five stories gained from the five teachers, it can be understood that either teachers and students face the same problems. Teaching and learning hortatory and analytical exposition texts is not easy. From the text itself, students get some difficulties in understanding the concept of the two texts (social function, generic structure, and lexicogrammatical features of the text). Students' confusion to distinguish the two genres is supported by the condition that they do not learn the genres in their primary language. Therefore, it is about a cultural clash. In addition, another cultural clash is students are not accustomed to expressing their arguments. On the other hand, in analytical and hortatory texts, the main points are presenting sequences of arguments in the body of the text. The condition becomes worse when students have low motivation to read. Consequently, it is hard for them to propose the suggestion and make the reiteration in the end of the texts. The last problem which is very common is dealing with lexicogrammatical features used in the text. Realizing the interweaving conceptual and substantial problems faced by students, teachers are required to teach writing culturally and systematically. It can be started by presenting some cases related to the students' social life then ask them to list some issues relating to the texts. When the students have known the purpose of the text, they will imagine and choose a topic that is appropriate to the function of the text. For the early steps, teachers might present some topics such as the issues that close to the students' life.

\section{REFERENCES}

Alfatia, V., \& Al-Hafizh, M. (2013). Teaching writing a hortatory exposition text to senior high school students by using an advertisement. Journal of English Language Teaching, 1(2), 128-134.

Bowkett, S. (2009). Countdown to creative writing. Oxon: Routledge.

Bilal, H. A., Tariq, A. R., Din, N. u., Latif, H., \& Anjum, M. N. (2013). Investigating the problems faced by the teachers in developing English writing skills. Asian Journal of Social Sciences \& Humanities, 238-244.

Brown, H. D. (2007). Prinsip pembelajaran dan pengajaran bahasa. (Noor Cholish and Yusi Avianto Pareanom, Translator). Jakarta: The US Embassy.

Brown, H. D. (2004). Language assessment principles and classroom practices. New York: Pearson Education, Inc.

Bruner, J. S. (1990). Acts of meaning. Cambridge, MA: Harvard University Press. 
Clandinin, D.J., \& Connelly, F.M. (1996). Teachers' professional knowledge landscapes: Teacher stories - stories of teachers, school stories - stories of school. Educational Researcher, 25(5), 2-14.

Clandinin, D.J., \& Connelly, F.M. (2000). Narrative inquiry: Experience and story in qualitative research. San Francisco: Jossey-Bass.

Harris, D. P. (1969). Testing English as a second language. New York: McGraw-Hill Book Company.

Gilstrap, R. L. (1991). Writing for social studies. In J. P. Shaver, Handbook of research on social studies teaching and learning. A project of the National Council for the social studies (pp. 578-587). New York: Macmillan Publishing Company.

Hess, N. (2001). Teaching large multilevel classes. Cambridge: Cambridge University Press.

Henry, A., \& Roseberry, R. L. (1996). A corpus-based investigation of the language and linguistic patterns of one genre and the implications for language teaching. Research in the Teaching of English, 472-489.

Hyland, K. (2004). Genre and second language writing. University of Michigan Press.

Indrowaty, S. A., Djatmika, D., Purnanto, D., \& Hariri, T. (2018, August). Analyzing the structure and the texture of Japanese advertisement (A systemic functional linguistics approach). In Fourth Prasasti International Seminar on Linguistics (Prasasti 2018). Atlantis Press.

Kramsch, C. (1993). Context and culture in languaeg teaching. Oxford: Oxford University Press.

Kroll, B. (1994). Second language writing. Research insight for the classroom. Sydnes: Cambridge University Press.

McDonough, J., \& Shaw, C. (2003). Materials and methods in ELT. Malden, USA: Blackwell Publishing, Ltd.

Moore, A. (2003). Teaching and learning: Pedagogy, curriculum, and culture. London: Routledge Fallmer.

Moore-Hart, M. A. (2010). Teaching writing in diverse classrooms, $k$-8: Enhancing writing through literature, real-life experiences, and technology. Pearson/Allyn and Bacon.

Oshima, A., \& Hogue, A. (1991). Writing academic English. California: Addison-Wesley Publishing Company.

Rahmatunisa, W. (2015). Problems faced by Indonesian EFL learners in writing argumentative essays. English Review: Journal of English Education, 3(1), 41-49.

Raimes, A. (2003). Ten Steps in Planning a writing course and training teachers of writing. In J. C. Richard, Methodology in language teaching (pp. 306-314). Cambridge: Cambridge University Press.

Richards, J. C., \& Renandya, W. A. (2003). Methodology in language teaching. Cambridge, United Kingdom: Cambridge University Press.

Richards, J. C., \& Schmitd, R. (2002). Dictionary of language teaching \& applied linguistics. Kuala Lumpur: Longman Publisher.

Stapleton, P. (2001). Assessing critical thinking in the writing of Japanese university students: Insights about assumptions and content familiarity. Written communication, 18(4), 506-548.

Stern, H. (1991). Fundamental concepts of language teaching. Oxford: Oxford University Press.

Seow, A. (2003). The writing process and process writing. In J. C. Richards, \& W. A. Renandya, Methodology in language teaching. An anthology of current practice (pp. 315-320). Cambridge: Cambridge University Press. 
Wang, S. (2009). Text types and dynamism of genres. Discourse of course: An overview of research in discourse studies.Amsterdam: John Benjamins Publishing Company

Wang, W. (2004). A contrastive analysis of letters to the editor in Chinese and English. Australian Review of Applied Linguistics, 27(1), 72-88.

Williams, C., Stathis, R., \& Gotsch, P. (2008). Speaking of writing: The significance of oral language in English learners' literacy development. Retrieved September Monday, 10, 2014, from Teacher Writing Center: www.teacherwritingcenter.org.

Yancey K. (2015) The social life of reflection: Notes toward an eportfolio-based model of reflection. In: Ryan M. (eds) Teaching reflective learning in higher education. Springer, Cham 